\author{
Control Rights over Intellectual Property: \\ Corporate Venturing and Bankruptcy Regimes \\ Sudipto Bhattacharya \\ Sergei Guriev
}

DISCUSSION PAPER NO 618

DISCUSSION PAPER SERIES

July 2008

Sudipto Bhattacharya has been Professor of Finance at LSE since 1995, prior to which he has taught at the Universities of Chicago, Stanford, Berkeley, Michigan, and Delhi. His main areas of research interest are corporate financial policy under asymmetric information, theories and regulation of banking activities cum crises, sharing of intellectual property under alternative institutional structures, and applied game theory. He has published around forty academic papers on these themes. Sergei Guriev is an Associate Professor of Economics and the Rector of the New Economic School in Moscow. He is also a President of the Center for Economic and Financial Research at the New Economic School. He received his Dr. Sc. (habilitation degree) in Economics (2002) and PhD in Applied Math from the Russian Academy of Science (1994), and M.Sc. Summa Cum Laude from Moscow Institute of Physics in Technology (1993). Any opinions expressed here are those of the authors and not necessarily those of the FMG. The research findings reported in this paper are the result of the independent research of the authors and do not necessarily reflect the views of the LSE. 


\title{
Control Rights over Intellectual Property: Corporate Venturing and Bankruptcy Regimes ${ }^{1}$
}

\author{
Sudipto Bhattacharya ${ }^{2}$ And Sergei Guriev ${ }^{3}$
}

First Draft: September 2006

Revised: July 2008

\footnotetext{
${ }^{1}$ This paper originates from our prior working paper, Bhattacharya and Guriev (2004). Work on this research project was begun when Bhattacharya was a Visiting Professor at the New Economic School in 2003. We thank the NES as well as Arizona State and Princeton Universities, for their very congenial research environments and financial support that have spurred our progress. We gratefully acknowledge helpful conversations with Patrick Bolton, Oliver Hart, Eric Maskin, and Per Stromberg, as well as seminar and conference participants in Princeton, Moscow, MIT Sloan, Gerzensee, without implicating them in any of the errors and omissions remaining in our paper.

${ }^{2}$ London School of Economics, and CEPR. E-mail: s.bhatt@lse.ac.uk

${ }^{3}$ New Economic School, Moscow, and CEPR. E-mail: sguriev@nes.ru
} 


\title{
Control Rights over Intellectual Property: Corporate Venturing and Bankruptcy Regimes
}

\begin{abstract}
We develop a theory of control rights in the context of licensing interim innovative knowledge for further development, which is consistent with the inalienability of initial innovator's intellectual property rights. Control rights of a downstream development unit, a buyer of the interim innovation, arise from its ability to prevent the upstream research unit from forming financial coalitions at the ex interim stage of bargaining, over the amount and structure of licensing fees as well as the mode of licensing, based either on trade secrets or on patents. We model explicitly the equilibrium choice of the temporal structure of licensing fees, and show that the innovator's ex interim financial constraint is more likely to bind when the value of her innovation is low. By constraining the financial flexibility of the upstream unit vis-a-vis her choice over the mode of licensing of her interim knowledge, the controlling development unit is able to reduce the research unit's payoff selectively in such contingencies. This serves to incentivise the research unit to expend more effort ex ante, to generate more promising interim innovations. We further show that such interim-inefficient control rights can nevertheless be renegotiation-proof.
\end{abstract}

JEL Codes: D23, K12, O32. 


\section{Introduction}

What is an appropriate, and empirically relevant, notion of control rights of one agent over another who generates and trades her intellectual property - in the form of an interim idea or innovation to be further developed by the controlling agent into a marketable invention? Can this notion be consistent with the empirically realistic assumption that innovator has inalienable intellectual property rights (IPR), in a sense related to that for the human capital of the entrepreneur in a financial contract, as in Hart and Moore (1994)? Specifically, when would such a notion of ex ante agreed control rights impact on the bargaining process between these two agents ex interim, over the licensing of any intellectual property generated by the innovator to her controlling partner? Can the possibility of such an impact be consistent with the inalienability of the innovator's IPR, in so far as she is entitled-in the event of disagreement over the terms of licensing with her controlling partner-to approach other partners for licensing her interim innovative ideas? Finally, what implications do control rights over intellectual property have for our understanding of the roles played by commonly observed institutional arrangements, such as corporate venturing? ${ }^{1}$

In this paper, we introduce a novel notion of Control Rights, given ex ante incomplete contracts, in a context of the licensing of intellectual property of observable but non-verifiable quality. We consider a setting of cumulative research and development (R\&D). An interim innovation, invented by an upstream research unit $(\mathrm{RU})$ is licensed to one of two competing downstream development units (DUs), who are the only parties capable - given deep pockets or other internal resources - of developing this innovation into a marketable product. We assume the inalienability of items of intellectual property from their originators. We then interpret our notion of control rights as those arising from bilateral contractual relationships between a research unit and a development unit, both of which are needed to bring innovative ideas to the market, in the form of Corporate Venturing. In particular, we emphasise the impact of our notion of control rights in corporate venturing on the equilibrium choice of the mode of licensing of the innovation, via patenting or via relying on trade secrets, which

\footnotetext{
${ }^{1}$ By corporate venturing, we refer to contractual arrangements via which (typically cash-rich) downstream development units-such as established pharmaceutical companies-initially finance cash-poor upstream research units-such as biotech startups-in return for certain control rights at the interim stage. These may include the right of first description and (refusal of) licensing of the research unit's interim innovation-such as a drug idea-as well as other restrictions on contracting with third parties.
} 
in turn affects the ex ante incentives of $\mathrm{RU}$ to invest in more rather than less promising innovation.

Some earlier literature on property rights in such cumulative R\&D processes, e.g. Aghion and Tirole (1994), has assumed that control rights over an upstream RU of a downstream DU gives the latter unconditional rights to make profitable use of any innovations by the former. Such a strong notion of control is at odds with empirical evidence even in the context of (ex-)employees of firms engaged in both research and development. ${ }^{2}$ We assume instead that allocation of control rights to a DU affects the affiliated RU's bargaining position, via constraining her away from finding financial coalition partners who may aid her (otherwise wealth-constrained) bargaining with the controlling DU. However, our RU always retains the right to patent her intellectual property and to license it to one or the other of the two competing DUs.

The licensing of interim innovations from RUs to DUs in our model is subject to a problem of ensuring that such knowledge transfers are in effect exclusive, so that a licensed item of interim innovative knowledge would not then be also sold clandestinely to competing DUs. $^{3}$ In our model, this is attempted to be ensured by one of two mechanisms, or modes of licensing of intellectual property.

One such mechanism involves the patenting of interim innovative knowledge prior to its dissemination and inviting competing bids for its licensing for further development. Patenting ensures exclusive licensing: if the RU makes a clandestine sale to a $\mathrm{DU}_{j}$ after exclusively licensing patented knowledge to a $\mathrm{DU}_{i}, \mathrm{DU}_{j}$ 's final invention would not be patentable and thus easily imitated - since it would embody codifiable aspects of the patented interim

\footnotetext{
${ }^{2}$ The researchers often manage to appropriate a substantial share of the surplus. Recently, a Japanese court enhanced the reward of an inventor, holding a patent jointly with his ex-employer, from 20,000 to 20 billion yen (189 million dollars); see New York Times (2004). Stakes are even higher in biotech-pharmaceutical licensing: the Hoffmann-La Roche's recent deal with Antisoma included a lump-sum payment of $\$ 43$ million plus 10-20 per cent of royalties on any products Roche brings to market. In theory, payments to Antisoma could exceed $\$ 500$ million if all existing products were successfully launched (Featherstone and Renfrey, 2004). The choice of contracts on revenue rather than on net profit may be driven by concerns such as in Anand and Galetovic (2000), of the possibility of the buyer inflating his reported expenditures to hold up the seller of the knowledge.

${ }^{3}$ In our companion paper, Bhattacharya and Guriev (2006), we show that exclusive (rather than multiple) licensing of knowledge to one of the competing DUs always maximizes the licensor's revenue.
} 
innovation. If the patented mode is chosen, then in our model a DU having control rights over its ventured upstream RU obtains no advantage whatsoever in the form or the extent of fees it would have to pay for an exclusive license. The cost of patenting, for the RU as well as her licensee DU, is a partial leakage of knowledge - arising from those aspects of it which are non-codifiable in the description for a patent - that would accrue to the non-licensee DU in the process of describing the interim innovation in public.

Alternatively, the RU could attempt to license her idea exclusively to a DU by relying on trade secrets. However, if she then clandestinely sells the same idea to some other DU(s), who may subsequently invent a marketable product, trade secret law would not preclude such a DU obtaining a patent in the event of her invention, on the pretext that he had rediscovered the idea himself. Hence, to ensure exclusive licensing by the RU to a DU, the latter would have to give the $\mathrm{RU}$ a share of potential post-invention revenues arising from developing the idea. The share should be sufficiently high to ensure that the knowledge would not be resold. In turn, that would diminish the incentives of such a licensee DU to develop the idea, thereby resulting in a lower probability of successful development.

In our companion paper, Bhattacharya and Guriev (2006), we develop a theory of optimal choices over these two modes of licensing, and their dependence on the levels of knowledge associated with innovative ideas, as well as on the extent of leakage of knowledge arising from descriptions thereof. In that paper we assume independence of RUs from DUs vis-a-vis choices over modes of licensing, and no binding financial constraints for the RU. ${ }^{4}$ However, it turns out that a financial constraint may indeed bind for an RU that is wealth-constrained when she prefers trade-secret-based licensing. The reason for this is that to ensure (credibly commit to) exclusive sale of her knowledge, she may need to be given such a high share of her licensee DU's post-invention revenue that, in the absence of ex interim transfers in the opposite direction, from the RU to the DU, any DU would prefer that the RU to patent her idea instead, and then solicit competing responses to offers for an exclusive licensing of the interim innovation.

If an $\mathrm{RU}$ is independent, and she has access to a financial coalition partner in the form of an outside Venture Capitalist who may advance her resources upon the realisation of her

\footnotetext{
${ }^{4}$ However, we did assume that the RU is precluded from developing her interim innovative idea/knowledge herself, owing to the prohibitive disincentive effects that would arise from her required external financing of development costs.
} 
interim innovation, RU could then make the requisite transfer to her licensee DU. She should be able to persuade her DU to accede to her preferred mode of licensing, provided that her venture capitalist ( $\mathrm{VC}$ ) partner has adequate expertise to ensure that the RU acts in the interest of their coalition in deciding on further clandestine sales to other DUs. This would occur when the total ex interim net expected surplus, given costly development prospects, is higher when a given item of knowledge is licensed without being patented.

However, as we show via an example below, it may be in the ex ante interest of a DU who has acquired control rights ex ante regarding such ex interim coalition formation by his controlled RU - to proscribe such financial coalitions, even at the expense of sacrificing ex interim optimal choice of the mode of licensing. This lack of ex interim financial flexibility is a commitment device that might provide $\mathrm{RU}$ with stronger incentives ex ante to aim for more promising interim innovation involving higher effort (in a manner analogous to that in Aghion and Bolton, 1992).

The reason for this is that, as we show in our companion paper, the extent and the value of the revenue share that must be given to $R U$ to ensure her exclusive licensing to a $\mathrm{DU}$ in the trade-secret-based mode, goes up when the RU's realised interim knowledge level is lower. Hence, the scenario above is more likely to arise for low knowledge levels and high levels of leakage of knowledge in the process of describing it, for a patent, or for a clandestine sale to a competing DU. As a result, if a controlling DU can ensure that his affiliated RU would have to patent and thereby obtain a low licensing fee when she generates low levels of knowledge ex interim, he would incentivise the RU to strive for higher knowledge levels, by expending further costly effort ex ante. In contrast, an RU financed independently, (e.g., by a venture capitalist, VC) may not have sufficient incentives to do so.

In fact, such a control right of a DU may itself be renegotiation-proof at the ex interim stage, despite the fact that the licensee DU allowing a RU-VC coalition to form at that point may enhance the overall surplus summed across RU and himself. That is the case when the controlling DU's ex interim expected payoff with patent-based licensing is no lower than the (for example symmetric, as in Rubinstein, 1982) share of this surplus he would obtain if he were to relax his control right, allowing a RU-VC coalition to go for trade secret-based licensing of the idea. The key contract law observation relevant here is that a potential RU-VC coalition could not make a legally binding promise to make a strictly higher payoff to a DU, than what he would obtain with a patent-based license from the RU, the only pre- 
existing contractual partner of the DU. In this respect, our example improves on those in Hart and Moore (2004), which also envisages control as ruling out ex-interim renegotiations over a subset of items in an ex ante contract, in a multi-dimensional contractual setting.

Our theory of what corporate venturing may accomplish thus entirely abstracts from any advantages that a DU partner may have over an ordinary financial partner, such as an independent venture capitalist (VC), in providing advice, or expertise, or monitoring services to an RU, as well as any disadvantages a DU may suffer from vis-a-vis usurping ex post surpluses attributable to inventions based on knowledge licensed from a partner RU. We also assume away all technological synergies specific to this particular DU. It is thereby complementary to the papers of Anand and Galetovic (2000), and Hellmann (2002). Our model shares some insights with Hellman (1998) where RU gives up control rights to a venture capitalist to protect the latter from RU's opportunistic behavior; like in our paper, in Hellman (1998) RU's financial constraints prevent the venture capitalist from providing incentives to RU via an equity stake. Yet, our model studies a richer setting where we distinguish between independent and strategic venture capitalists, where RU's stake has an impact on next-stage development, and where the outcome depends on the mode of licensing which in turn is chosen endogenously, given the ex ante contractual relationships.

The main empirical predictions of our theory are straightforward. Other things equal, namely holding constant the quality of the interim innovation we would expect to see a higher likelihood of patenting by RUs in corporate venturing relationships. Any additional efficiency of the research (cum development) processes in such corporate venturing entities may have nothing to do with a direct efficiency-enhancing impact of DUs' venturing on the effectiveness of RUs' research, but with advantageous bargaining "distortions" it brings about. Moreover, our theory would predict that the formation of such corporate venture-based (funding of) RU ties is more likely to arise in fields in which the extent of knowledge leakage from patenting is high, not because an independent RU would not choose trade secret-based licensing ex interim then, but because denying her flexibility in doing so is more likely to be in the ex ante interests of controlling DUs, for lower levels of interim knowledge. Further research on the differences between venture financing by the downstream development unites versus independent financiers, and its implications for research performance and patenting needs thereof, is awaited.

We also consider a modification of our setup to address the relationship of our results 
to those in some related literature on the impact of soft versus tough (debtor- vs. creditor-

friendly) bankruptcy laws on innovative firms. Our analysis suggests that softer bankruptcy laws, allowing senior debtor-in-possession (DIP) financing for failed DUs in financial distress, may enable efficiency-enhancing trade-secret based licensing of further second-round or fallback applications arising from an innovative idea. This also implies that softer control rights, emerging from independent rather than corporate venture financing (from downstream DUs) are more likely to be observed in the "new economy" sectors. In these sectors, innovations are often "multi-faceted"; their most promising applications of interim ideas are less likely to be fully understood right away.

Our paper proceeds as follows. Section 2 presents the model; we describe the equilibrium choice of licensing mode and structure of licensing fees assuming away financial constraints. Section 3 discusses the role of the ex ante control rights in the context of an example where reallocation of control rights to the DU provides $\mathrm{RU}$ with stronger incentives to exert research effort. In Section 4, we consider implications of our analysis for the impact of soft versus tough bankruptcy laws on innovative firms. Section 5 concludes.

\section{The model}

\subsection{The setup}

The model is similar to the one in our companion paper Bhattacharya and Guriev (2006). There are three risk-neutral agents: a research unit RU and two competing development units $\mathrm{DU}_{1}$ and $\mathrm{DU}_{2}$. These parties undertake research (by RU) and development (by DUs) to create a new product. The investments in research and development are sequential. First, RU produces knowledge $K \in[0,1]$. This knowledge is an input in the development stage which may result in the creation of a new product. If only one DU develops successfully, he obtains a monopoly rent of $V=1$ in the product market. If two DUs succeed in development, they compete a la Bertrand and both get zero rents.

We assume $K$ to be the outcome of a random process with a distribution $G(K ; e)$ that depends on RU's costly effort choice, $e$, ex ante. For each DU, his probability $P$ of successful development is a function of his acquired knowledge and choice of subsequent non-contractible 


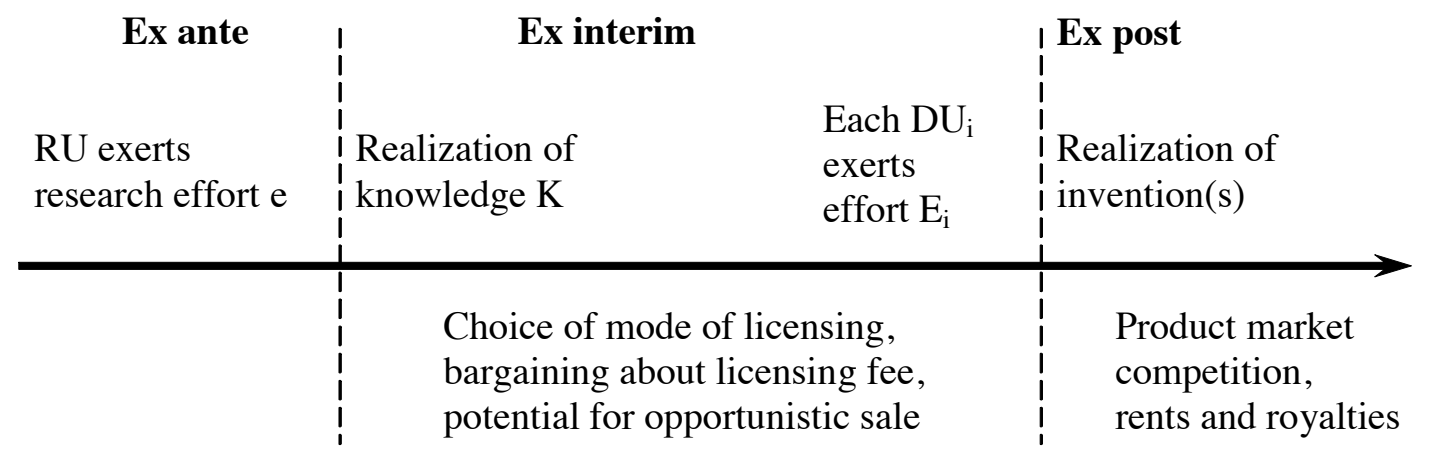

Figure 1: Timing

development effort $E \in[0,1 / 2]:$

$$
P=p(K, E)=\sqrt{2 K E}
$$

The efforts $e$ and $E$ are measured in terms of their costs, which are assumed to be nonverifiable. Knowledge is metrized in terms of the maximum probability of successful secondstage invention it may lead to. The constraint $E \leq 1 / 2$ is to make sure that this probability cannot exceed 1. However, in all equilibria considered in the paper $E \leq K / 2=$ $\arg \max _{E}[\sqrt{2 K E}-E]$, so that this constraint is never binding. ${ }^{5}$ We describe the processes of choice over modes of knowledge licensing, and bargaining on the division of surplus, which serve to endogenise DUs' effort choices.

Both DUs have deep pockets, while RU is financially constrained.

\subsection{Timing and assumptions}

The timing of events is presented in the Figure 1.

Ex ante, the parties choose an allocation of control rights: either (i) RU and DUs are independent, or (ii) one DU has control over RU. Then RU invests $e$ in knowledge generation.

Ex interim, knowledge $K$ is realized. The parties choose the mode of licensing of RU's knowledge, and bargain over the licensing fee. The bargaining game in each mode, with and

\footnotetext{
${ }^{5}$ Most of the qualitative results in this paper generalise to a setting in which DU's indirect cost function $C(P ; K)$ for generating the probability of invention $P$ given knowledge $K$ satisfies the following conditions. The cost function $C(P ; K)$ should be strictly increasing and convex in $P$; cost $C$ and the marginal cost $\partial C / \partial P$ are strictly decreasing in $K$. Throughout the paper we will use $C(P ; K)=P^{2} /(2 K)$.
} 
without patenting, is described below (further details are provided in our companion paper Bhattacharya and Guriev, 2006). There are two alternative modes of knowledge licensing. One is the open, or patent-based mode, and the other one is closed, or trade-secret-based mode. In the open mode, a patent is registered, so that RU can commit to sell her knowledge to one party only. RU describes her knowledge publicly which leads to a partial leakage of her knowledge; an exogenous proportion $L \in[0,1]$ of the capability $K$ is transferred to both DUs. Both DUs also infer the level of RU's knowledge $\mathrm{K}$ from this description. The firm $i$ that licenses the full content of RU's knowledge pays RU a lump-sum fee $F_{o}$ and chooses development effort $E_{i}$; the resulting probability of development is $P_{i}=p\left(K, E_{i}\right)$. The other firm $j$ chooses effort $E_{j}$, and its probability of development is $P_{j}=p\left(L K, E_{j}\right)$. These effort choices $\left\{E_{i}, E_{j}\right\}$ form Nash equilibrium strategies in the post-licensing subgame between the licensee and non-licensee DUs.

In the closed mode, knowledge licensing occurs through a private sale of $K$ to one of the DUs, who is randomly chosen by an independent $\mathrm{RU}$ or is the $\mathrm{DU}_{i}$ who has control rights over RU owing to an ex ante corporate venturing arrangement. The parties bargain about their licensing contract, with its payoffs contingent in part on $\mathrm{DU}_{i}$ 's post-invention revenues, which serves the role of eliminating RU's incentive to make a clandestine second sale of the knowledge $K$ to the other $\mathrm{DU}_{j}$. As the ex post outcome is binary $(V=1$ or $V=0$ ), this contract includes only two variables: a lump-sum transfer $F_{c}$ from $\mathrm{DU}_{i}$ to $\mathrm{RU}$ and RU's royalty share $s$ in $\mathrm{DU}_{i}$ 's ex post revenues. To initiate the bargaining, RU provides a description of her knowledge, which is sufficient for $\mathrm{DU}_{i}$ to infer its level $\mathrm{K}$. This description leads to some partial leakage of RU's knowledge, $L K$, to $\mathrm{DU}_{i} \cdot{ }^{6}$ After $\mathrm{RU}$ and $\mathrm{DU}_{i}$ agree on the terms of licensing, RU reveals the full content of her knowledge to the licensee $\mathrm{DU}_{i}$, and $\mathrm{DU}_{i}$ chooses his development effort $E_{i}$. We denote $P_{c}$ as his resulting choice of the probability of final invention.

RU could also sell her knowledge to $\mathrm{DU}_{j}$ subsequently. In this opportunistic deviation by RU, she would first describe her knowledge to $\mathrm{DU}_{j}$; this would cause leakage $L K$. If they agree on a fee for RU disclosing the full content of her knowledge, $\mathrm{DU}_{j}$ would then choose the probability of development $P_{d}$ (where $d$ stands for 'deviation') given the $\mathrm{DU}_{i}$ 's choice of

\footnotetext{
${ }^{6}$ We assume the same degree of leakage in open and closed modes. While such assumption is realistic, it is not essential for our results; see Bhattacharya and Guriev (2006) for the analysis of a more general setup with different degrees of leakage in open and closed modes.
} 
$P_{c}$. If $\mathrm{RU}$ and $\mathrm{DU}_{j}$ fail to agree upon the licensing fee, $\mathrm{DU}_{j}$ would develop on the basis of leaked knowledge $L K$; in this case we denote his choice of probability of invention as $Q_{d}$. By choosing RU's revenue share $s$ appropriately, $\mathrm{DU}_{i}$ will try to prevent RU's disclosing her knowledge $K$ to $\mathrm{DU}_{j}$. If $s$ is sufficiently high, RU could be interested in protecting $\mathrm{DU}_{i}$ 's ex post rents from competition (this effect is mentioned in Pisano, 1989); we characterize when this is feasible.

We assume equal bargaining power in ex interim bilateral bargaining between a DU and an RU.

\subsection{Interim payoffs}

We will denote as $T_{c}$ and $T_{o}$ the total ex interim equilibrium expected surplus of RU cum the licensee DU in the closed and in the open mode, respectively. We will denote as $U_{o i}\left(P_{i}, P_{j} ; K\right)$ the expected ex interim payoff of this DU in the development race in the open mode, whereas the other $\mathrm{DU}_{j}$ chooses probability of invention $P_{j}$ to maximize $U_{o j}\left(P_{j}, P_{i} ; L K\right)$. According to (1), $\mathrm{DU}_{i}$ 's effort cost is $E_{i}=P_{i}^{2} /(2 K)$ so that in the open mode

$$
U_{o i}=\left[\left(1-P_{j}\right) P_{i}-P_{i}^{2} /(2 K)-F_{o}\right]
$$

which increases in $K$ and decreases in $P_{j}$. Since $F_{o}$ is paid before the development effort is chosen, the $\mathrm{DU}_{i}$ 's payoff (2) is maximized at $P_{i}=K\left(1-P_{j}\right)$. The competing $\mathrm{DU}_{j}$ develops on the basis of leaked knowledge $L K$; he maximizes his payoff

$$
U_{o j}=\left[\left(1-P_{i}\right) P_{j}-P_{j}^{2} /(2 L K)\right]
$$

by choosing $P_{j}=L K\left(1-P_{i}\right)$.

Correspondingly, in the closed model of knowledge sale the licensee DU obtains:

$$
U_{c}=\left[(1-s) P_{i}-P_{i}^{2} /(2 K)-F_{c}\right]
$$

where $P_{c}$ is the optimal choice of $P_{i}$ in this mode. The RU's payoff consists of the royalty $s P_{c}$ and the cash payment $F_{c}$ made before the choice of development effort. For simplicity, we assume that the non-licensee $\mathrm{DU}_{j}$ has no development capabilities in equilibrium. The licensing terms, $F_{c}$ and $s$, are chosen via bilateral bargaining between $\mathrm{RU}$ and $\mathrm{DU}_{i}$; the contract terms incentivise $\mathrm{RU}$ not to sell her knowledge to $\mathrm{DU}_{j}$ later. 


\subsection{The mode of licensing and the structure of licensing fees}

The bargaining structure above implies that the choice of the mode would be made according to whether or not the total (subgame- perfect) equilibrium payoffs summed across the RU and her licensee DU, $T_{o, c}$ is higher in the open or the closed mode of licensing, unless RU's financial constraint is binding. Suppose that the level of RU's required revenue share $s$ to ensure an exclusive closed-mode sale is so high that RU has to make a lump-sum payment to her licensee $\mathrm{DU}_{i}$ to persuade her to choose the closed mode $\left(F_{c}<0\right)$. As RU's wealth constraint precludes her making the payment, the parties may have to patent the knowledge for licensing, even though $T_{c}>T_{o}$. This happens whenever $T_{c}-s P_{c}<T_{o}-F_{o}$. As we show in the next Section, this has important implications for the organizational structure of $R \& D$, which in turn affects the ex ante incentives of RU to expend effort for higher levels of knowledge. We now summarise the results in our companion paper Bhattacharya and Guriev (2006), regarding equilibrium payoffs of the RU and her licensee DU.

Open mode. If a patent is registered then (the exclusive licensee) $\mathrm{DU}_{i}$ pays $\mathrm{RU}$ a licensing fee $F_{o}$ and obtains knowledge $K$. At the same time, knowledge $L K$ is leaked to the public domain, so the competing $\mathrm{DU}_{j}$ can also engage in the development contest. The joint surplus of $\mathrm{RU}$ and $\mathrm{DU}_{i}$ will therefore equal $T_{o}=\left[U_{o i}+F_{o}\right]$; see (2). The competing $\mathrm{DU}_{j}$ will use the leaked knowledge $L K$, and will therefore receive $\left[\left(1-P_{o}\right) Q_{o}-Q_{o}^{2} /(2 L K)\right]$. Here the probabilities $\left\{P_{o}, Q_{o}\right\}$ satisfy the Nash equilibrium conditions:

$$
\begin{aligned}
P_{o} & =\arg \max _{p}\left[\left(1-Q_{o}\right) p-p^{2} /(2 K)\right]=K\left(1-Q_{o}\right), \\
Q_{o} & =\arg \max _{q}\left[\left(1-P_{o}\right) q-q^{2} /(2 L K)\right]=L K\left(1-P_{o}\right) .
\end{aligned}
$$

For each pair of $K$ and $L$ the solution is unique:

$$
P_{o}=\frac{K-L K^{2}}{1-L K^{2}} ; \quad Q_{o}=\frac{L K-L K^{2}}{1-L K^{2}} .
$$

Essentially, the sequential offers (to $\mathrm{DU}_{i}$, then to $\mathrm{DU}_{j}$ if rejected by $\mathrm{DU}_{i}$ ) bargaining process in this mode results in Bertrand competition between the two DUs: RU extracts all the additional surplus of the licensed DU, making his participation constraint bind. The equilibrium payoffs of the RU and DU, characterised in Bhattacharya and Guriev (2006), 
are as follows:

$$
T_{o}=\frac{K(1-L K)^{2}}{2\left(1-L K^{2}\right)^{2}} ; \quad F_{o}=\frac{K(1-L)}{2\left(1-L K^{2}\right)} ; \quad U_{o}=T_{o}-F_{o}=\frac{K(1-K)^{2} L}{2\left(1-L K^{2}\right)^{2}} .
$$

Closed mode. If the contracting parties do not register a patent but choose disclosure via a closed sale, there is no leakage to outsiders in equilibrium. However, in order to provide $\mathrm{RU}$ with incentives not to disseminate knowledge to the competing $\mathrm{DU}_{j}, \mathrm{DU}_{i}$ has to give away a sufficient share $s$ of his ex post revenues in royalties to RU, so that:

$$
\left[s P_{c}-s P_{c}\left(1-P_{d}\right)\right] \geq\left[\left\{\left(1-P_{c}\right) P_{d}-P_{d}^{2} /(2 K)\right\}-\left\{\left(1-P_{c}\right) Q_{d}-Q_{d}^{2} /(2 L K)\right\}\right]
$$

where $P_{c}$ is chosen by the licensee $\mathrm{DU}_{i}$ and $\left\{P_{d}, Q_{d}\right\}$ are the potential choices of the other $\mathrm{DU}_{j}$ if the RU attempts to sell knowledge to her. $P_{d}$ is chosen by $\mathrm{DU}_{j}$ if she has full knowledge, and $Q_{d}$ is her choice with leaked knowledge $L K$. For a given share $s$, the left-hand side in (6) is the reduction in the RU's expected payoff due to opportunistic disclosure to $\mathrm{DU}_{j}$. The right hand side is the maximum licensing fee that $\mathrm{RU}$ may extract from $\mathrm{DU}_{j}$ in case she decides to disclose to him after licensing her knowledge to $\mathrm{DU}_{i}$. The logic of calculating this licensing fee is very similar to the one in patent-based licensing: since the process of negotiating the fee results in a partial leakage of knowledge $L K, \mathrm{RU}$ can obtain from $\mathrm{DU}_{j}$ at most the expression in the right-hand side. If and only if (6) is violated, there exists a fee that $\mathrm{DU}_{j}$ will be willing to pay and $\mathrm{RU}$ will be willing to accept in exchange for the clandestine second sale.

While giving a sufficiently high share of ex post revenues to RU rules out opportunistic disclosure, it comes at a cost of lowering the licensed DU's incentives to apply effort. Indeed, by solving for optimal effort of $\mathrm{DU}_{j}$ and $\mathrm{DU}_{i}$ we find that $P_{c}$ decreases in $s$ :

$$
\begin{aligned}
P_{d} & =\arg \max _{p}\left[\left(1-P_{c}\right) p-p^{2} /(2 K)\right]=K\left(1-P_{c}\right) ; \\
Q_{d} & =\arg \max _{q}\left[\left(1-P_{c}\right) q-q^{2} /(2 L K)\right]=L K\left(1-P_{c}\right) ; \\
P_{c} & =\arg \max _{p}\left[(1-s) p-p^{2} /(2 K)\right]=K(1-s) .
\end{aligned}
$$

In equilibrium, RU and $\mathrm{DU}_{i}$ will choose the minimum possible $s \in[0,1]$ that satisfies (6). Substituting (7)-(9) into (6) we find

$$
s K(1-s) \geq(1-K(1-s))(1-L) / 2 .
$$

Solving this inequality we derive 
Lemma 1 A mechanism for a closed knowledge sale, which is incentive-compatible for no further disclosure by the $R U$, requires $R U$ to be given a (minimum) share $s=s^{*}(K ; L)$ in her licensee DU's post-invention revenues, where $s^{*}(K ; L)$ satisfies:

$$
s^{*}(K ; L)=\left(1+L-\sqrt{(1+L)^{2}-8(1-L)(1 / K-1)}\right) / 4<1 / 2 .
$$

The licensee DU develops with probability $P_{i}=P_{c}=K\left(1-s^{*}(K ; L)\right)$, the other DU does not develop. This closed mode licensing is only feasible if such $s^{*}(K ; L)$ exists, i.e., whenever $K \geq \widehat{K}(L)$, where

$$
\widehat{K}(L)=\left(1+\frac{(1+L)^{2}}{8(1-L)}\right)^{-1} .
$$

Proof. See Bhattacharya and Guriev (2006).

Whenever the closed mode is incentive-compatible, the RU's share $s^{*}(K ; L)$ decreases with $K$. Indeed, a higher $K$ raises the probability of successful development; since selling the innovation to two competing developers would result in a higher ex post rent dissipation due to Bertrand competition. Therefore RU has incentives not to disclose to the second DU even if her share $s$ is small. Furthermore, the value of RU's stake in post-invention revenues $s P_{c}$ decreases in $K$. Clearly, whenever $s=s^{*}(K ; L)$ exists, it decreases in $K$, and so that right-hand side of $(10)$ decreases in $K$. Therefore the left-hand side $s K(1-s)=s P_{c}$ also decreases in $K$. The joint surplus of $\mathrm{RU}$ and $\mathrm{DU}_{i}$

$$
T_{c}=P_{c}-P_{c}^{2} /(2 K)=K\left(1-s^{*}(K ; L)^{2}\right) / 2
$$

is increasing in $K$. This joint surplus is concave in $K$ and approaches $K / 2$ as $K$ increases; although $s^{*}(K ; L)$ decreases in $K$, its rate of decrease slows down at higher levels of $K$.

\section{Control rights and ex ante incentives}

The solution above neglects the RU's ex interim financial constraint. RU's financial constraint $F_{c} \geq 0$ may become binding ex interim, when her minimum incentive compatible equity stake $s P_{c}$ is sufficiently high. Straightforward calculations yield $F_{c}=(1-3 s)(1-s) K / 4$. Therefore, the RU's financial constraint, $F_{c} \geq 0$, is binding whenever $s^{*}(K, L)>1 / 3$. This results in potential ex interim inefficiency: there may arise a situation where the joint surplus is higher in the closed mode $T_{c}>T_{o}$ but the licensee $\mathrm{DU}_{i}$ prefers the open mode. This disagreement occurs whenever $\left(T_{o}-F_{o}\right)>\left(T_{c}-s P_{c}\right)$. If RU had deep pockets, she would pay 
$\mathrm{DU}_{i}$ at the interim stage for forgoing the open mode option, but since RU is cash constrained the ex interim efficient mode can only be implemented if she has some external source of financing. First, we consider a situation where the parties ex ante agree on the RU remaining independent. In this case the RU may overcome this ex interim inefficiency using outside venture capital. The second scenario is corporate venturing where RU may commit ex ante to remain financially constrained ex interim through giving control rights to $\mathrm{DU}_{i}$.

If $\mathrm{RU}$ is independent and requires external financing ex interim, she may join forces with a venture capitalist (VC) who will provide cash to pay the licensee $\mathrm{DU}_{i}$ the amount $I=\left[\left(T_{o}-F_{o}\right)-\left(T_{c}-s P_{c}\right)\right]$ ex interim, in exchange of $I / P_{c}$ shares out of the $s$ share of $\mathrm{DU}_{i}$ 's revenue accruing to its coalition with the $\mathrm{RU}$. It is crucial that such a $\mathrm{VC}$ is able to make sure that RU acts in the interest of the RU-VC coalition, so that RU does not disseminate knowledge to $\mathrm{DU}_{j}$ even though she only has a stake of $s-I / P_{c}$ in $\mathrm{DU}_{i}$ revenues. We believe that this is a reasonable assumption: VC is not a regular financial intermediary, but a specialized entity with reputational concerns, which can prevent opportunistic behavior by its coalition partner.

The second scenario is corporate venturing. Ex ante, $\mathrm{RU}$ and $\mathrm{DU}_{i}$ agree that $\mathrm{RU}$ will cede control rights to $\mathrm{DU}_{i}$. We do not assume alienability of RU's intellectual capital. The transfer of control rights implies only that RU's outside financing can be vetoed by $\mathrm{DU}_{i}$. Also, RU is required to start negotiations with $\mathrm{DU}_{i}$ first and is not allowed to sell to a competing $\mathrm{DU}_{j}$ exclusively in a closed sale with a share in $\mathrm{DU}_{j}$ 's revenues. ${ }^{7}$ It is easy to see that under corporate venturing, $\mathrm{DU}_{i}$ could credibly veto a $\mathrm{RU}-\mathrm{VC}$ alliance. One way to commit to this veto is to sign a contract ex ante that if RU signs any share contracts with outsiders, her partner $\mathrm{VC}$ must pay $\mathrm{DU}_{i}$ a sufficiently high penalty for a breach of her ex ante agreement with $\mathrm{DU}_{i}$. We also assume that $\mathrm{RU}$ cannot make a binding promise to the $\mathrm{DU}_{i}$ about any prospective ex imterim payment, before forming a coalition with a VC.

As corporate venturing rules out relaxing RU's financial constraint, it may result in knowledge licensing via the open mode when the closed mode is ex interim efficient. Why would parties want to sign such a contract? The reason is that although the independent RU scenario is efficient ex interim, it may provide perverse incentives ex ante. As shown above, unlike $F_{o}$ or $T_{c} / 2$ the value of RU's revenue share $s P_{c}$ is decreasing in $K$. Therefore

\footnotetext{
${ }^{7}$ In the closed mode the disclosure of knowledge to $\mathrm{DU}_{j}$ cannot be tracked but any revenue sharing contract between RU and a third party is by definition verifiable.
} 
the RU's financial constraint $F_{c} \geq 0$ tends to bind at low levels of $K$. By forcing open mode sales via corporate venturing for such knowledge levels, $\mathrm{DU}_{i}$ may indeed create ex interim inefficiencies. However, he may also improve RU's ex ante incentives to invest costly effort in research which is more likely to produce higher levels of $K$.

Whether corporate venturing is efficient ex ante depends on the relative strength of these ex ante and ex interim effects. Let us consider a simple example where RU can choose one of two effort levels: high or low. The high level of effort costs her $e$ dollars more, but also produces higher knowledge $K=K^{H}$ ex interim with probability 1 . The low effort produces only $K=K^{L}$ with probability 1 , where $K^{L}<K^{H}$.

Suppose that in both states the closed mode dominates the open mode: $T_{c}^{k}>T_{o}^{k}, k=$ $L, H$; in the high state RU's financial constraint is not binding, while in the low state $s^{L} P_{c}^{L}>\max \left\{T_{c}^{L} / 2, T_{c}^{L}-T_{o}^{L}+F_{o}^{L}\right\}$. The latter implies $s^{L} P_{c}^{L}>F_{o}^{L}$ so the RU's financial constraint is binding in the low state. Then corporate venturing matters in the low state, and will affect the RU's payoff if a lower level of effort is chosen ex ante.

Proposition 1 Corporate venturing will strictly increase RU's research effort if

$$
\begin{aligned}
& \max \left\{T_{c}^{H} / 2, F_{o}^{H}\right\}-e<s^{L} P_{c}^{L}-I^{L} \text { and } \\
& \max \left\{T_{c}^{H} / 2, F_{o}^{H}\right\}-e>F_{o}^{L} .
\end{aligned}
$$

Corporate venturing will be adopted ex ante if the change in research effort is cost-efficient:

$$
\left(T_{c}^{H}-e\right)-T_{c}^{L}>0
$$

Since the closed mode is more efficient in the low state, $s^{L} P_{c}^{L}-I^{L}=F_{o}^{L}+T_{c}^{L}-T_{o}^{L}>F_{o}^{L}$, the conditions (15) are consistent for some effort costs $e$.

Table 1 describes a numerical example where the conditions above are satisfied for a range of parameter values $e$. We consider the case with $L=0.8, K^{L}=1 / 3$, and $K^{H}=1 / 2$. Indeed, the conditions (14)-(16) imply $e>0.123-0.069=0.054, e<0.123-0.037=0.086$, and $e<0.246-0.14=0.106$. Hence, for all $e \in(0.054,0.086)$ corporate venturing strictly increases ex ante welfare and will therefore be an equilibrium outcome.

Notice that in this example, for $K=K^{L}$, DU's payoff in the open mode $U_{o}=T_{o}-F_{o}=$ 0.071 binds as an outside option relative to her symmetric share of the surplus in the close 


\begin{tabular}{|l|l|l|}
\hline & $K=K^{L}$ & $K=K^{H}$ \\
\hline$K$ & 0.33 & 0.5 \\
\hline$L$ & 0.8 & 0.8 \\
\hline$T_{o}$ & 0.108 & 0.141 \\
\hline$T_{c}$ & 0.140 & 0.246 \\
\hline$F_{o}$ & 0.037 & 0.063 \\
\hline$T_{o}-F_{o}$ & 0.071 & 0.078 \\
\hline$T_{c} / 2$ & 0.070 & 0.123 \\
\hline$s$ & 0.4 & 0.130 \\
\hline$P_{c}$ & 0.2 & 0.431 \\
\hline$s P_{c}$ & 0.08 & 0.056 \\
\hline$T_{c}-s P_{c}$ & 0.06 & 0.189 \\
\hline$I$ & 0.011 & - \\
\hline$s P_{c}-I$ & 0.069 & - \\
\hline
\end{tabular}

Table 1: A numerical example where corporate venturing is ex ante efficient.

mode $T_{c} / 2=0.070$. Thus, DU would not expect to be made an offer of a payoff greater than 0.071 if she were to allow the RU to form a coalition with VC ex interim. Hence, her enforcement of the control right that precludes RU from forming a financial coalition with a third party $\mathrm{VC}$ is therefore renegotiation-proof ex interim.

In this example, corporate venturing allows $\mathrm{DU}_{i}$ to commit to force the choice of the open mode when $K$ is low and RU's financial constraint is binding $s P_{c}>\max \left\{F_{o}, T_{c} / 2\right\}$. Since corporate venturing makes the commitment credible, RU expects to suffer from the open mode, and therefore prefers to choose a higher level of effort to produce greater knowledge $K$ whereby her financial constraint does not bind. Once the high effort level is taken ex ante, corporate venturing actually becomes irrelevant ex interim (financial constraint is not binding in the high state); hence corporate venturing does not even result in ex interim inefficiency. The latter is an artefact of our assumption that high effort level rules out the low knowledge state with probability 1 . If the low knowledge state occurred under high effort with an interior probability, the results in Proposition 1 could be easily generalized; but corporate venturing would now create a non-trivial probability of ex interim inefficiency 
in the licensing process. ${ }^{8}$ Indeed, thereby corporate venturing firms may patent more often.

It is important to emphasize that our main qualitative point, concerning the impact of RU's interim wealth constraint (requiring $F_{c}>0$ ) on the equilibrium choice of the mode of licensing does not depend on the specific parameterization of the model above. The mode choice is driven by the shape of the boundary in $\{K, L\}$ space across which $T_{c}(K, L)-$ $T_{o}(K, L)$ changes sign; this boundary is characterized in detail in our companion paper. But our argument does not depend on the exact form of this boundary. The only qualitative property we require for our main insight is the possibility of the RU and DU disagreeing over their preferred modes of licensing ex interim, given DU's wealth constraint, that is $\left(T_{o}-F_{o}\right)>\left(T_{c}-s P_{c}\right)$, for lower levels of $K$ at which $T_{c}(K, L)$ still exceeds $T_{o}(K, L)$. For this possibility to arise, it is sufficient (but far from necessary) that the expected value of the RU's invention-contingent revenue or royalty $s P_{c}$ (i) is decreasing in $K$ and (ii) exceeds $T_{c} / 2$ for low $K$. The specific development cost function, based on Cobb-Douglas production function (1), is only one of many convex cost functions which would give rise to this somewhat counter-intuitive property of the incentive-compatible contract. ${ }^{9}$

\footnotetext{
${ }^{8}$ As we show in our companion paper, such "inefficiency" need not be socially suboptimal, once one takes into account the non-licensee DU.

${ }^{9}$ Indeed, instead of Cobb-Douglas function $E=P^{2} / 2 K$ utilized in our model (and further characterized in our companion paper), let us consider a general function $E=C(P, K)$. From the analogue of equation (6), we see that $s P_{c}$ as a function of the underlying knowledge $K$ and leakage $L$, must satisfy the incentivecompatibility condition:

$$
s P_{c}>\left[\left\{\left(1-P_{c}\right)-C\left(P_{d}, K\right) / P_{d}\right\}-\left(Q_{d} / P_{d}\right)\left\{\left(1-P_{c}\right)-C\left(Q_{d}, L K\right) / Q_{d}\right\}\right]
$$

This inequality would bind for any efficient licensing contract. For the inequality's right-hand side to be strictly decreasing in $K$ it is sufficient that (i) $P_{c}(K, L)$ be strictly increasing in $K$, (ii) $C(P, K) / P$ be strictly increasing in $P$ (which is implied by the strict convexity of $C(\cdot)$ in $P$ ), and (iii) $Q_{d}(L K ; K) / P_{d}(K ; K)$ be weakly increasing in $K$, given $L$, which is supported by our results for licensing in the open mode; it is also an intuitive property for a larger set of cost functions $C(\cdot)$.
} 


\section{Control rights in bankruptcy and incentives for in- novation}

The main result above is driven by the role of control rights in situations where financing constraints are binding. It is therefore directly related to the allocation of control in bankruptcies and should be compared to the recent literature on the effect of bankrupty laws on innovation. A recent example of this literature is Acharya and Subramanian (2007), who conduct an extensive cross-country and cross-sectors empirical analysis. Their theoretical and empirical results suggest a thesis seemingly counter to ours, on the efficacy of downstream DU control rights. They suggest, and provide supporting empirical evidence for, a beneficial impact of "soft", or debtor-friendly, residual control rights in the bankruptcy process, that is greater for firms and industries which they classify as being more innovative based on patents as well as citation counts. This effect is shown by Acharya and Subramanian to hold across countries, as well as over time in response to changes in bankruptcy laws, after adjusting for other effects such as dependence on external financing, and the extent of financial development. In this section we show that our argument is consistent with their empirical results, although we have a different mechanism in mind.

In essence, Acharya and Subramanian argue in their modeling that greater control rights of debtor firms regarding continuation of investment in projects with initially disappointing returns, result in relatively higher efficiency gains for innovative firms. In these firms lower early returns are more likely, but even moderate early returns augur significantly higher later returns, as compared to non-innovative (conservative, or low-risk) lines of investment. In the Acharya and Subramanian model, this effect arises from frictions in debt rescheduling. ${ }^{10}$

We briefly suggest here a connection between our thesis, relating to the potential impact of third-party outside financing for the interim efficiency of the licensing of innovation, and their results on the differential impact of debtor-friendly laws or regimes in handling bankruptcy

\footnotetext{
${ }^{10}$ Scheduled early repayment obligations in their model are assumed to be entirely non-renegotiable, in the form of enhancement of later repayments in response to shortfalls of early cash flows relative to repayment obligations. In our opinion, these debt renegotiation frictions may be minor for innovative firms, both in absolute terms and relative to those for firms with widely held debt. Indeed, many smaller innovative firms are funded by knowledgeable and flexible financiers such as venture capitalists, and larger ones often have very deep pockets to absorb short-term failures due to cash flows from past patents.
} 
for more innovative firms and sectors relative to "traditional" sectors. Specifically, we may think of such a debtor-friendly regime as being supportive of debtor-in-possession financing, as in the US Chapter 11. Let us consider a modification of our example in Section 3, in which costly ex ante research effort may yield two potential paths for further development. Assume for simplicity that these are mutually exclusive: both of these may fail but both can not succeed at the same time. Then the optimal development path is to proceed first with the initially more promising path, entailing a maximal success probability $K^{H}$, with costly development requiring external financing leading to a chosen probability $P^{H}$ of success.

If this first path of development fails, then the firm that tried to develop it is still left with the intellectual property of the other potential path of development. Suppose that this other path entails the (possibly revised) maximal success probability $K^{L}<K^{H}$. However, the level of debt overhang from the failed first development effort is too high for that developer to credibly invest in the second line of invention. Hence, it needs to license this innovative idea to another DU, and the surplus-maximizing mode of doing so, which is also important for the maximization of ex ante research incentives, is the closed or trade-secret based one. However, as in the example of Section 3 above, to do such licensing in an incentive compatible way for a lower level of knowledge $K^{L}$ may require the aid of a third-party (specialized) outside financier. The outside funding is needed to advance the amount of funds $I_{c}$ required for the licensor to give the bankrupt DU the requisite revenue or royalty share. It is also likely that a new financier would be willing to do so if and only if its claim to these potential royalties in future is senior to those of the pre-existing creditors who financed the failed first effort.

Allowing debtor-in-possession financing in these contingencies would clearly be of help. Note that our line of advocacy for debtor-friendly bankruptcy laws in circumstances like the above is based on the need to enhance the interim efficiency of the disposal of residual intellectual property of the bankrupt firm. Our argument does not require the fixity of the claims of other creditors, nor does it assume that it is the insolvent firm which would somehow continue in the same line of business. What it does presuppose is that the idea involved in the initially failing invention process is multi-faceted, entailing more than one possible line of development with different ranges of outcomes, even products. For example, consider transistors in the early stages, when its inventors left AT\&T, the firm within which the initial innovation occurred, to pursue other lines of application.

Such a multi-faceted characteristic of innovative ideas is perhaps more likely to be true 
in the sectors commonly labeled as the "new economy", in which their technological possibilities and frontiers, and lines of application, are not yet fully discernible. In contrast, even innovative ideas in more traditional "old economy" sectors might be on average more uni-dimensional: an idea either succeeds for its envisaged application post development, or it fails and has no other use for it. However, ideas still differ in their qualities, metrized as the maximal probability of their successful development, and higher quality ideas are generated (made more likely) only with greater costly ex ante effort. In such sectors, the control aspect of corporate venturing, via its impact on generating incentives for research units to undertake such effort, may matter more.

As an empirical measure, the ratio of citation to patent counts in a sector might serve as a statistic suitable for judging the multi-faceted characteristics of innovative ideas in it. It would be interesting to study if the prevalence of institutions such as corporate venturing-as opposed to independent VC financing-across diverse sectors of an economy, is correlated with such a characteristic, as well as with more commonly studied (qualitative) features, such as the extent of leakage from disclosure in patents. ${ }^{11}$

\section{Concluding remarks}

In this paper, we have elucidated a theory of control rights in the context of licensing interim innovative knowledge for further development, which is consistent with the inalienability of initial innovator's intellectual property rights. Control rights of a downstream development unit (a buyer of interim innovations), arises from his ability to prevent the affiliated upstream research unit (the innovation's seller) from forming financial coalitions at the ex interim stage of bargaining, over the amount and structure of licensing fees, as well as the mode of licensing, based on trade secrets or on patenting. By constraining the flexibility of the upstream unit in this manner, the controlling development unit is able to reduce the research unit's payoffs, in contingencies where the latter generates lower levels of interim knowledge. This provides the research units with greater incentives to expend costly effort ex ante, helping to generate more productive interim innovations.

\footnotetext{
${ }^{11}$ Our model also implies desirability of sector-specific variation in bankruptcy rules with softer rules for the "new" sectors. In principle, sector-specific bankruptcy rules are already included in the Chapter 11 (e.g. Section 11.10), albeit for a different reason.
} 
Our idea shares a family resemblance with that of Hart and Moore (2004), who also view control rights as emanating from dimensions other than just property rights (over assets or intellectual capital), in the form of ruling out ex interim renegotiations over some items in a multi-aspect contract. Doing so may create better ex ante incentives, when contracts are incomplete owing to the non-verifiabilty of some ex interim circumstances. Our construction has the feature that, in some circumstances, the control right to preclude potential coalition formation with third parties would not be renegotiated ex interim. Even if formation of a financial coalition could potentially improve the ex ante contracting parties' joint ex interim payoff, the ex ante contract would remain renegotiation-proof, as long as potential outside coalition partners cannot make legally binding payoff promises to the other parties prior to the formation of their financial coalition with a contracting party.

Other authors have considered the advantages and disadvantages of potential development units (DU), versus independent venture capitalists as financial partners of wealthconstrained upstream research units (RU). In particular, Anand and Galetovic (2002) consider the tradeoffs between the higher efficiency generated by DU partners, versus their abilty to usurp profits due to the innovation in a multi-product enterprise, and Hellmann (2002) considers the incentives of DU partners to develop and market final inventions that are substitutes vs. complements to their existing products. Gompers and Lerner (2000) emphasize the importance of strategic fit between RU and DU for the success of corporate venturing. Our exploration of the implications of corporate venturing differs from all of these, and emphasizes considerations related to the bargaining processes in licensing of intellectual property.

We also point out that potential importance of third-party interim financing in the licensing of intellectual property may help explain the ex ante superiority of soft (debtor-friendly) rather than hard (creditor-friendly) bankruptcy regimes. This would arise when interim innovative ideas may be multi-faceted in the sense of having diverse and mutually exclusive development paths; some of these that are initially perceived to be more promising may fail to succeed. Together, our results and this observation suggest further avenues of both empirical and theoretical research, in particular of the impact of corporate versus independent venture financing on innovative activity, and patenting proclivity, on their respective optimality - along with that of differing bankruptcy regimes - for innovative activities in the "old" vs "new" sectors of an economy. 


\section{REFERENCES}

Acharya, V., and Subramanian, K. (2008), "Bankruptcy Codes and Innovation", Mimeo, London Business School.

Aghion, P., And Bolton, P. (1992), "An Incomplete Contracts Approach to Financial Contracting", Review of Economic Studies, 59 (3), 473-494.

Aghion, P., And J. Tirole (1994), "On the Management of Innovations", Quarterly Journal of Economics, 1185-1209.

Anand, B., And Galetovic, A. (2000), "Weak Property Rights and Holdup in R\&D", Journal of Economics and Management Strategy 9, 615-642.

Bhattacharya, S., and Guriev, S. (2004), "Knowledge Disclosure, Patents and Optimal Organization of Research and Development", CEPR Discussion Paper 4513, London: CEPR.

Bhattacharya, S., and Guriev, S. (2006), "Patents vs. Trade Secrets: Knowledge Licensing and Spillover", Journal of the European Economic Association, 4(6):11121147

Featherstone, J., and Renfrey, S. (2004), "Licensing Gambles: Raising the Stakes", Nature Reviews: Drug Discovery, vol. 3, 107-108.

Gompers, P., And Lerner, J. (2000), "The Determinants of Corporate Venture Capital Successes: Organizational Structure, Incentives, and Complementarities", in R. Morck (ed.), Concentrated corporate ownership. University of Chicago Press.

Hart, O., And Moore, J. (1994), "A Theory of Debt Based on the Inalienability of Human Capital," Quarterly Journal of Economics, 109 (4), 841-79.

Hart, O., And Moore, J. (2004), "Agreeing Now to Agree Later:Contracts that Rule Out but Do Not Rule In", mimeo, Harvard University.

Hellmann, T. (1998), "The Allocation of Control Rights in Venture Capital Contracts", RAND Journal of Economics 29 (1), 57-76, . 
Hellmann, T. (2002), "A Theory of Strategic Venture Investing", Journal of Financial Economics 64, 285-314.

New York Times (2004), "Inventor Wins a Round in Tokyo Court", Jan 31, 2004.

Pisano, G. (1989), "Using Equity Participation to Support Exchange: Evidence from the Biotechnology Industry", Journal of Law, Economics, and Organization 1, 109-26.

Rubinstein, A. (1982), "Perfect Equilibrium in a Bargaining Model", Econometrica 50, $97-11$ 